\title{
CENTRAL VENOUS CATHETERISATION- PERILS AND PITFALLS IN CRITICAL CARE
}

\author{
Vidya Sanjay Nagar1, Deniskumar Vasharambhai Patel2, Basavaraj Sajjan³, Rudrarpan Chatterjee
}

${ }^{1}$ Associate Professor, Department of General Medicine, Grant Medical College and Sir JJ Hospital.

${ }^{2}$ Senior Resident, Department of General Medicine, Grant Medical College and Sir JJ Hospital.

$3 J u n i o r$ Resident, Department of General Medicine, Grant Medical College and Sir JJ Hospital.

4Junior Resident, Department of General Medicine, Grant Medical College and Sir JJ Hospital.

\begin{tabular}{l}
\hline ABSTRACT \\
BACKGROUND \\
Central venous catheterisation is ubiquitous in the critical care unit. Catheter related deep venous thrombosis is now recognised as \\
a dreaded complication of this commonly used process.
\end{tabular}

a dreaded complication of this commonly used process.

\section{MATERIALS AND METHODS}

Observational prospective study. Patients admitted in critical care who underwent central venous catheterisation were followed up. Endpoint for screening for venous thrombosis with Doppler was clinical symptoms or 24 hours after removing central venous catheter. Incidence of catheter related deep venous thrombosis and risk factors for the same were evaluated.

\section{RESULTS}

The risks of venous thrombosis are multifactorial and pertain to patients as well as the catheter itself. Gender, obesity, thrombocytosis, leucocytosis, duration of catheterisation, diameter of the catheter and site of catheterisation were all associated with catheter related deep venous thrombosis.

\section{CONCLUSION}

Once developed, catheter related deep venous thrombosis presents challenging clinical as well as medicolegal issues. This study elaborates on factors predisposing to catheter related deep venous thrombosis.

\section{KEYWORDS}

Central Venous Catheterisation, Venous Thrombosis, Doppler, Critical Care.

HOW TO CITE THIS ARTICLE: Nagar VS, Patel DV, Sajjan B, et al. Central venous catheterisation- perils and pitfalls in critical care. J. Evolution Med. Dent. Sci. 2017;6(23):1890-1893, DOI: 10.14260/Jemds/2017/415

\section{BACKGROUND}

Central Venous Catheterisation (CVC) is a necessary evil of the critical care unit. When Seldinger, in 1953, described his revolutionary technique of overwire catheterisation little would he have anticipated the widespread use and abuse of the same in today's intensive care.[1] First described in the infusion of high volume fluids into the subclavian vein in military casualties in 1952, all long-term CVC's are designed such that the tip dwells at the junction of the superior vena cava and the right atrium.[2] Roughly grouped into the tunnelled catheters with an anchoring cuff, non-tunnelled catheters, implantable ports, peripherally inserted central catheters and dialysis catheters they may be single, double or triple lumen with consequent increases in diameter. The smallest diameter would naturally be preferable, but multiple lumens are required especially in critical care for infusing multiple drugs and monitoring central venous pressure.[3] Possible associated morbidities include early complications of arterial puncture, pneumothorax or subsequent catheter related thrombosis, infections and thromboembolism. This study aimed to look at the complication of Catheter Related Deep Venous Thrombosis (CRDVT).

Financial or Other, Competing Interest: None.

Submission 08-02-2017, Peer Review 08-03-2017,

Acceptance 14-03-2017, Published 20-03-2017.

Corresponding Author:

Dr. Rudrarpan Chatterjee,

Room No. 409, 300 Resident Doctor's Hostel,

JJ Hospital, Byculla, Mumbai-400008.

E-mail: rudi,gmc2009@gmail.com

DOI: $10.14260 /$ jemds $/ 2017 / 415$

\section{(c) (i) $\$$}

CRDVT may be asymptomatic and manifest directly as an embolic episode or account for a host of symptoms such as associated pain, dilatation of superficial veins, swelling and tenderness of the associated limb or the superior vena cava syndrome with dyspnoea, facial flushing and swelling, neck pain, headaches or a sensation of head fullness. Often the only indicator may be a difficulty in infusing drugs or aspirating from the catheter. Pulmonary embolism has been detected in up to $15 \%$ of patients with symptomatic CRDVT and fatal pulmonary embolism can occur. [4] Contemporary studies have shown that the incidences of symptomatic CRDVT are $5 \%$, whereas the incidence of asymptomatic CRDVT is $14 \%$ $18 \% .^{[5]}$ In this study we investigated the influence of catheter design, material, insertion, location and technique, position of catheter tip and other factors in contributing to the development of CRDVT in the critical care unit.

\section{Aims and Objectives}

To study the incidence of catheter related deep venous thrombosis in the critical care unit and patient and catheter related risk factors for the same.

\section{MATERIALS AND METHODS}

An observational prospective study was conducted on 100 successive patients admitted to the critical care unit at a tertiary care centre who underwent a central venous catheterisation. Sample size was estimated as per prevalence of catheter related deep venous thrombosis in literature of $18 \%$ at $95 \%$ confidence intervals with a precision of 0.1 . Patients greater than 12 years of age admitted in the critical care unit who underwent a central venous catheterisation 
were included in the study. Patients with a history of previous thrombosis in the same vein, previous catheterisation of the veins in current or past admission and those with local trauma to the site were excluded. Patients were enrolled in the study after obtaining written informed consent.

Patients were evaluated and followed up from the time of insertion of central venous catheter in the critical care unit and followed up till discharge or demise. Detailed medical history and examination was carried out. Indications for which catheter insertion was performed were noted. Side, site, diameter, material, numbers of lumen and number of attempts at catheterisation were noted. Patient with PICCs (Peripherally Inserted Central Catheter) were also assessed for superficial thrombophlebitis. In case of haemodialysis catheter, venous pressure and use of heparin during dialysis was noted. Subjects were assessed stringently for symptoms of CRDVT. CRDVT was diagnosed by Doppler ultrasonography of concerned vessel of patients who developed symptoms and by routine Doppler within 24 hours of removal of central venous catheter in asymptomatic patients.

Continuous variables were summarised by using summary statistics (number of observations, mean and standard deviation with range). Categorical values were estimated by using frequencies and percentages. In this study, comparison of presence of CRDVT and Symptomatic CRDVT were associated with multiple risk factors by using Chi Square Test. Student's ' $t$ ' test were used for continuous variables. All statistical tests were interpreted at $5 \%$ level of significance.

\section{RESULTS}

A total of 100 patients were enrolled in the study with 65 having central venous catheters and 35 having haemodialysis catheters. CRDVT manifested in 34 patients with a mean age of 43.95 years with a standard deviation of 15.3 years. Thus, incidence of CRDVT was $34 \%$.

20 of the 65 patients $(30.76 \%)$ with central venous catheters and 14 out of 35 patients (40\%) with haemodialysis catheters developed CRDVT. Out of 34 patients of CRDVT 16 (16\%) patients had symptomatic CRDVT, while 18 (18\%) patients were asymptomatic.

No significant association was found between the age of the patient and risk of developing CRDVT. (Table 1) 22 $(37.9 \%)$ of the male cases developed CRDVT which was more as compared to $12(28.6 \%)$ of the female cases, but the difference was not significant. Male patients had a statistically significant $(\mathrm{p}<0.001)$ higher probability of developing symptomatic CRDVT than their female counterparts (13 out of 22 and 3 out of 12 for symptomatic male and female patients respectively). No significant association was present between the major organ system involved and the risk of developing CRDVT. Out of the 14 patients (40\%) with CRDVT from haemodialysis catheter, no significant association was found with either chronic kidney disease and acute kidney injury and majority were asymptomatic (8 out of 14).
On stratifying patients according to Body Mass Index (BMI), obesity was found to have significant association with the development of CRDVT ( $n=23, p<0.05)$. A history of smoking was not found to have significant association with CRDVT. Patients with thrombocytosis were found to have significant association with CRDVT, though no significant association was found with white blood cell counts.

Femoral vein catheterisations had the highest incidence of symptomatic ( $\mathrm{n}=9, \mathrm{p}<0.05)$ as well as total CRDVT ( $\mathrm{n}=13, \mathrm{p}<0.05$ ), while the subclavian vein had the least $(\mathrm{n}=4)$ (Figure 1).

For haemodialysis catheters, femoral vein catheterisation also accounted for most number of CRDVT (32.3 episodes of CRDVT per 1000 catheter days), while internal jugular vein was associated with the least (16.9 episodes of CRDVT per 1000 catheter days) (Figure 2). The mean period of catheterisation for those who developed CRDVT was 15.5 days with a standard deviation of 5.04 , while it was 20.92 days with a standard deviation of 7.5 in those with haemodialysis catheters. There was significant increase in development of CRDVT with prolonged catheterisation $(\mathrm{n}=26, \mathrm{p}<0.05)$ in both groups (Table 2). Mean of average venous dialysis pressure in patient who had catheter related thrombosis was $29.69 \mathrm{mmHg}$ with a standard deviation of $9.75 \mathrm{mmHg}$, which was higher than patients who did not have catheter related thrombosis of $23.22 \mathrm{mmHg}$ with a standard deviation of $07.01 \mathrm{mmHg}$. No association was found between the side of insertion of catheter, the number of attempts at venous puncture and the incidence of CRDVT.

\begin{tabular}{|c|c|c|}
\hline $\begin{array}{c}\text { Age Group } \\
\text { (Years) }\end{array}$ & $\begin{array}{c}\text { CRDVT } \\
(\mathbf{N}=\mathbf{3 4}) \mathbf{~ N o} \%\end{array}$ & $\begin{array}{c}\text { Symptomatic CRDVT } \\
(\mathbf{N}=\mathbf{1 6}) \mathbf{~ N o} \%\end{array}$ \\
\hline $13-19(\mathrm{~N}=06)$ & 0116.7 & -- \\
\hline $20-29(\mathrm{~N}=16)$ & 0850.0 & 0637.5 \\
\hline $30-39(\mathrm{~N}=20)$ & 0525.0 & 0105.0 \\
\hline $40-49(\mathrm{~N}=24)$ & 0729.2 & 0104.2 \\
\hline $50-59(\mathrm{~N}=13)$ & 0861.5 & 0430.8 \\
\hline $60-69(\mathrm{~N}=12)$ & 0325.0 & 0325.0 \\
\hline$\geq 70(\mathrm{~N}=09)$ & 0222.2 & 0111.1 \\
\hline $\mathrm{N}=100$ & 34 & 16 \\
\hline
\end{tabular}

Table 1. Age Distribution of Cases with Catheter related Deep Venous Thrombosis showing No Significant Association with Age $-p>0.05$

\begin{tabular}{|c|c|c|}
\hline \multicolumn{2}{|c|}{$\begin{array}{c}\text { No. of Days of CVC } \\
\text { use Mean + SD }\end{array}$} & $\begin{array}{c}\text { No. of Days of HDC } \\
\text { use Mean + SD }\end{array}$ \\
\hline CRDVT present & $\begin{array}{c}15.55+5.04 \\
(\mathrm{n}=20)\end{array}$ & $20.92+7.5(\mathrm{n}=14)$ \\
\hline CRDVT absent & $\begin{array}{c}9.68+4.99 \\
(\mathrm{n}=45)\end{array}$ & $13.95+4.44(\mathrm{n}=21)$ \\
\hline T & 4.3472 & 3.1308 \\
\hline DF & 36 & 19 \\
\hline P value (<0.05) & 0.000108 & 0.005504 \\
\hline Result & Significant & Significant \\
\hline $\begin{array}{c}\text { Table 2. Mean Duration of Catheter use and Relation to } \\
\text { CRDVT. CVC-Central Venous Catheter. HDC- Haemodialysis } \\
\text { Catheter. T- Value of Student's 't' Test. DF- Degrees of } \\
\text { Freedom }\end{array}$ \\
\multicolumn{3}{|c|}{} \\
\hline
\end{tabular}




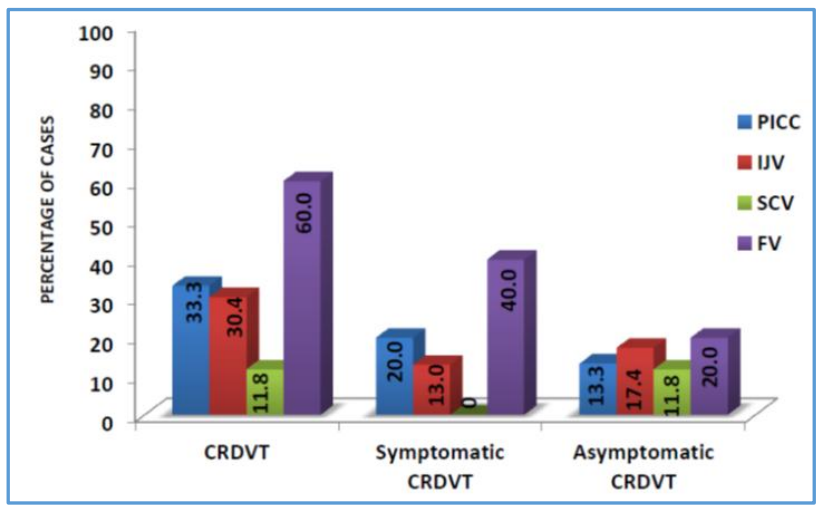

Figure 1. Incidence of CRDVT in Patients expressed as Percentages according to Site of Central Venous Line Insertion. PICC-Peripherally Inserted Central Catheter. IJV-Internal Jugular Vein. SCV-Subclavian Vein. FV-Femoral Vein.

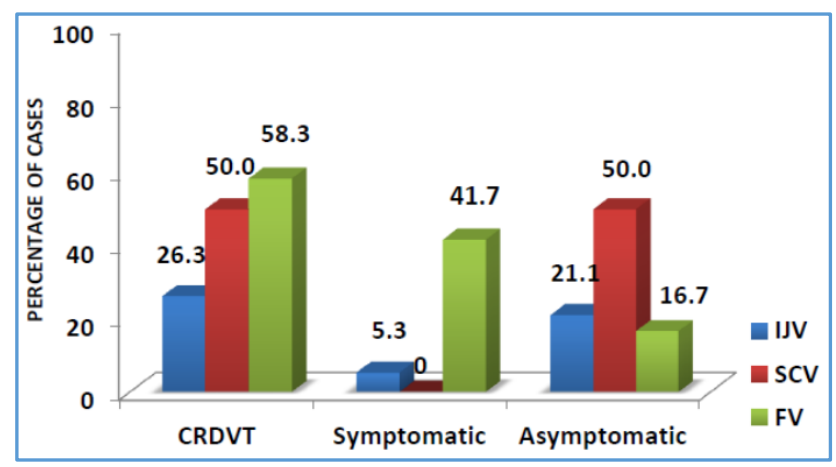

Figure 2. Incidence of CRDVT Expressed in Percentages according to Site of Haemodialysis Catheter Insertion. IJVInternal Jugular Vein. SC-Subclavian Vein. FV-Femoral Vein

\section{DISCUSSION}

The incidence of CRDVT in our study was 34\%. We studied patient related factors and catheter related factors and their influence on the development of CRDVT. There was no demonstrable association between age of the patient and CRDVT, which is discordant with the study by Van Roden et al which found an increasing risk of CRDVT with increasing age, proposed to be due to increased secretion of procoagulant von Willebrand factor and plasminogen activator inhibitor by the vascular endothelium.[6] Male sex was associated with higher probability of symptomatic CRDVT in accordance with previous studies.[7],[8] A Body Mass Index (BMI) of greater than 25 was associated with a significant risk of developing CRDVT in our study. Obesity is a known risk factor for CRDVT.[8] Adipocytokines such as leptin and adiponectin can enhance the activity of the coagulation system and decrease fibrinolytic activity. A history of smoking is expected to be thrombogenic due to increased tissue factor levels. It did not, however, have significant association with CRDVT in our study. Multiple studies have demonstrated the increased incidence of CRDVT in smokers.[9] A possible reason for discordance might be the inaccuracy of history, which was elicited from the relatives and not the patients themselves, as our study was based in the critical care unit. Thrombocytosis and leucocytosis were both risk factors associated with increased incidence of CRDVT, though statistical significance was demonstrated only for the former. These are acute phase reactants, which are often raised in patients in critical care and should therefore serve as red flags for those who might be considered at risk for CRDVT in the critical care unit.[8],[10]

Of the catheter related factors, site of insertion seems to have significant risks with minimum risk for subclavian catheters and maximum for femoral vein catheters in our study. For haemodialysis catheters, internal jugular vein was associated with the least risk of CRDVT. Multiple studies have confirmed this in the past.[11],[12],[13] In addition, femoral catheters tend to lose patency earlier due to the proximity to the hip joint. The tendency of femoral thrombi to embolise makes femoral catheters particularly high risk. Our study was concordant with existing literature in the fact that larger diameter catheters were associated with higher risk of CRDVT with the highest incidence in triple lumen catheters.[14] The larger diameter causes venous stasis and more turbulent blood flow and hence promotes thrombosis. Left sided catheter insertion was found to have greater risk of thrombosis in studies by Van Rooden et al and Kamphuisen et al, estimated to be due to difficult insertion and resulting in endothelial injury.[3],[6] We found no such association. Multiple attempts at catheterisation also demonstrated no significant risk in our study, though there is evidence for the same in literature.[15] High venous pressure during dialysis can be used as a predictor of development of CRDVT. The indwelling time of central venous catheter was found to be the most important predictive factor for the development of CRDVT.[16] Developing a protocol to minimise time of catheterisation to that absolutely required would cause significant reduction in CRDVT and associated mortality.

\section{CONCLUSION}

Multiple risk factors predict the development of CRDVT in the critical care unit including male sex, obesity, inflammatory states, site of catheterisation, diameter of the catheter used and average venous pressure. CRDVT not only causes significant morbidity, but in the fragile setting of the critical care unit may even lead to mortality. The central venous catheter should be considered, not just as a venous access device but as an intervention with several ramifications. Judicious use of central venous catheters is the need of the hour. An individualised hospital policy for selection of patients, monitoring and timely removal of catheters would perhaps help reduce the complications of the same.

\section{REFERENCES}

[1] Seldinger SI. Catheter replacement of the needle in percutaneous arteriography: a new technique. Acta Radiologica 1953;39(5):368-76.

[2] Aubaniac R. Subclavian intravenous injection: advantages and technic. Press Med 1952;60(68): 1456.

[3] Kamphuisen PW, Lee AY. Catheter related thrombosis: lifeline or a pain in the neck? Hematology Am Soc Hematol Educ Program 2012;2012(1):638-44.

[4] Monreal M, Alastrue A, Rull M, et al. Upper extremity deep venous thrombosis in cancer patients with venous access devices--prophylaxis with a low molecular weight heparin (Fragmin). Thromb Haemost 1996;75(2):251-3. 
[5] Lee AY, Kamphuisen PW. Epidemiology and prevention of catheter-related thrombosis in patients with cancer. J Thromb Haemost 2012;10(8):1491-9.

[6] Van Rooden CJ, Tesselaar MET, Osanto S, et al. Deep vein thrombosis associated with central venous catheters - a review. J Thromb Haemost 2005;3(11):2409-19.

[7] Craft PS, May J, Dorigo A, et al. Hickman catheters: leftsided insertion, male gender and obesity are associated with an increased risk of complications. Aust N Z J Med 1996;26(1):33-9.

[8] Shi Y, Wen L, Zhou Y, et al. Thrombotic risk factors in patients undergoing chemotherapy via peripherally inserted central catheter. Journal of International Medical Research 2014;42(3):863-9.

[9] Pan L, Zhao Q, Xiangmei Yang X. Risk factors for venous thrombosis associated with peripherally inserted central venous catheters. Int J Clin Exp Med 2014;7(12):5814-9.

[10] Khorana AA, Connolly GC. Assessing risk of venous thromboembolism in the patients with cancer. J Clin Onco 2009;27(29):4839-47.
[11] Taylor RW, Palagiri AV. Central venous catheterization. Crit Care Med 2007;35(5):1390-6.

[12] Gentile A, Petit L, Masson F, et al. Subclavian central venous catheter-related thrombosis in trauma patients: incidence, risk factors and influence of polyurethane type. Critical Care 2013;17(3):R103.

[13] Maya ID, Allon M. Outcomes of tunneled femoral hemodialysis catheters: comparison with internal jugular vein catheters. Kidney International 2005;68(6):2886-9.

[14] Evans RS, Sharp JH, Linford LH, et al. Risk of symptomatic DVT associated with peripherally inserted central catheters. Chest 2010;138(4):803-10.

[15] Lee AY, Levine MN, Butler G, et al. Incidence, risk factors and outcomes of catheter-related thrombosis in adult patients with cancer. J Clin Oncol 2006;24(9):1404-8.

[16] Chopra V, Ratz D, Kuhn L, et al. Peripherally inserted central catheter-related deep vein thrombosis: contemporary patterns and predictors. J Thromb Haemost 2014;12(6):847-54. 